\title{
The International Year of the Salmon Pan-Pacific High Seas Expedition 2022
}

\author{
Caroline Graham ${ }^{1}$, Stephanie Taylor ${ }^{2}$, Vladimir Radchenko ${ }^{1}$, Evgeny Pakhomov ${ }^{3,4,5}$, Ed Farley ${ }^{6}$, Laurie \\ Weitkamp $^{7}$, Dick Beamish ${ }^{8}$, Brian Riddell ${ }^{9}$, Jackie King ${ }^{8}$, Chrys Neville ${ }^{8}$, Shunpei Sato ${ }^{10}$, Shigehiko Urawa ${ }^{10}$, \\ Aleksey Somov ${ }^{11}$, Aleksandr Starovoytov ${ }^{11}$, Sang-Seon Yun ${ }^{12}$, Erika Anderson ${ }^{8}$, Tim Van Der Stap ${ }^{5}$, and \\ Mark Saunders ${ }^{1}$ \\ ${ }^{1}$ North Pacific Anadromous Fish Commission, Suite 502, 889 West Pender Street, Vancouver, British Columbia, \\ Canada, V6C 3B2, Canada \\ ${ }^{2}$ Island Diesel Way, Fisheries and Oceans Canada, 1965 Island Diesel Way, Nanaimo, BC, V9S 5W8, Canada \\ ${ }^{3}$ Institute for the Oceans and Fisheries, University of British Columbia, 2202 Main Mall, Vancouver, British \\ Columbia, V6T 1Z4, Canada \\ ${ }^{4}$ Department of Earth, Ocean, and Atmospheric Sciences, University of British Columbia, 2207 Main Mall, \\ Vancouver, British Columbia, V6T 1Z4, Canada.
}

${ }^{5}$ Hakai Institute, PO Box 25039, Campbell River, British Columbia, V9W 0B7, Canada

${ }^{6}$ Auke Bay Laboratory, Alaska Fisheries Science Center, National Marine Fisheries Service, National Oceanic and Atmospheric Administration, 11305 Glacier Highway, Juneau, Alaska, 99801, USA

${ }^{7}$ Newport Field Station, Northwest Fisheries Science Center, National Marine Fisheries Service, National Oceanic and Atmospheric Administration, 2032 Southeast Oregon State University Drive, Newport, Oregon, 97365, USA

${ }^{8}$ Pacific Biological Station, Fisheries and Oceans Canada, 3190 Hammond Bay Road, Nanaimo, British Columbia, V9T 6N7, Canada

${ }^{9}$ Pacific Salmon Foundation, 1682 W 7th Ave, Vancouver, British Columbia, V6J 4S6, Canada

${ }^{10}$ Fisheries Resources Institute, Japan Fisheries Research and Education Agency, 2-2 Nakanoshima, Toyohira-ku, Sapporo 062-0922, Japan

${ }^{11}$ Pacific Scientific Research Fisheries Center (TINRO-Center) 4, Shevchenko Alley, Vladivostok, 690091, Russia

${ }^{12}$ Big River Scientific LLC, Mukilteo, Washington, USA

Keywords: salmon, winter, high seas, North Pacific, expedition, international

Pacific salmon are an important cultural, commercial, and biological resource for countries of the North Pacific Rim. Salmon and the people that depend on them are faced with increasing uncertainty as climate and ecosystems undergo significant changes with serious social and ecological implications. As conditions become more variable and salmon returns become more unpredictable, the need to understand factors affecting salmon during all life history stages intensifies. Winter is the least studied and thus least understood period in the life history of Pacific salmon (Myers et al. 2016). As part of the International Year of the Salmon (IYS), the North Pacific Anadromous Fish Commission (NPAFC) with its five member countries (Canada, Japan, the Republic of Korea, the Russian Federation, and the United States) is planning a Pan-North Pacific high seas research expedition in late winter 2022 to build upon two related IYS international expeditions, which were conducted in the Gulf of Alaska during the winter of 2019 and 2020 (Pakhomov et al. 2019; Somov et al. 2020). Given the challenges of completing an international survey during the pandemic, the difficult decision was made to postpone the multivessel research expedition from early 2021 to the winter of 2022.

As many as five research vessels with researchers from five countries will concurrently survey the North Pacific in winter 2022 (Fig. 1). The overarching objective is: "To demonstrate the utility of an international panPacific winter ecosystem survey to understand how increasingly extreme climate variability in the North Pacific Ocean and associated changes in the physical environment influence the abundance, distribution, migration, growth, fitness and survival of Pacific salmon and surrounding species." We have been working with a group of scientists from around the North Pacific Rim to address a set of four sub-objectives: (1) determine species and stock-specific ocean distributions and relative abundances, and the condition of juvenile, immature/mature Pacific salmon within the study area, and factors/mechanisms controlling them; (2) document the spatial and temporal variation in physical and biological oceanographic conditions; (3) document the distribution, condition, and standing stocks of zooplankton and nekton that serve as the prey base for Pacific salmon and associated marine fishes; and (4)

All correspondence should be addressed to C. Graham. 
demonstrate the ability to effectively collaborate across the five NPAFC parties and our partners to conduct integrated ecosystem research that will support the sustainable management of salmon in a rapidly changing North Pacific Ocean.

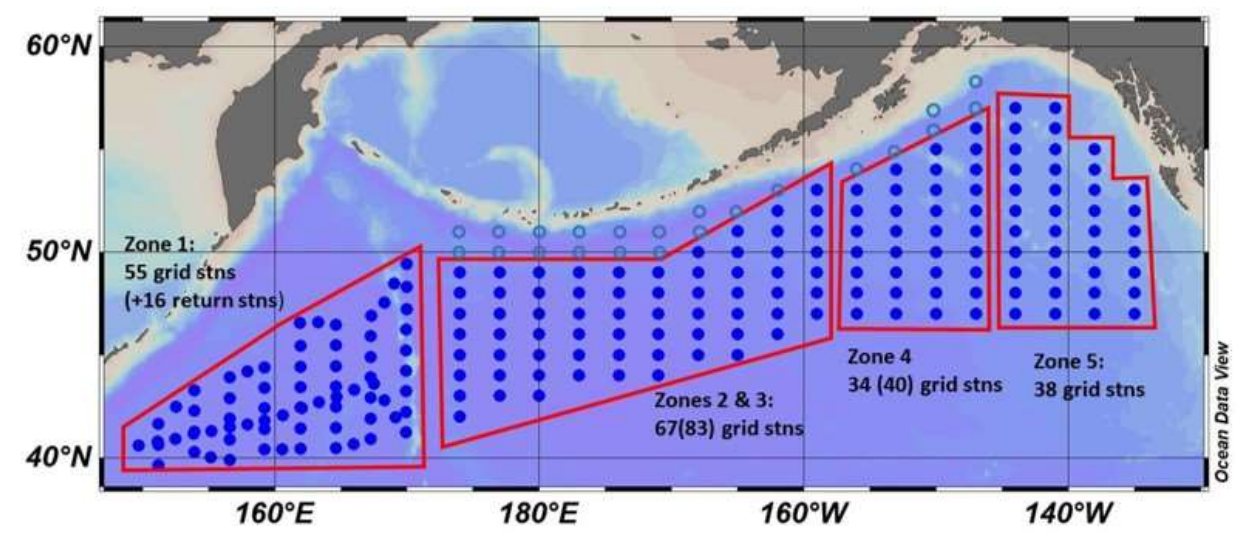

Fig. 1. The 2022 IYS Pan-Pacific Winter High Seas Expedition survey map. The expedition will cover five zones: zone 1 will tentatively be covered by a Russian vessel, zones $2 \& 3$ will be tentatively covered by a Russian charter vessel, zone 4 by a US vessel and zone 5 by a Canadian vessel.

Lead scientists from each country and experts in specific research areas are developing a cruise plan with research protocols that all ships involved will adhere to. This expedition will be novel for a number of reasons, including the data mobilization efforts and technologies that will be applied. All data collected on the 2022 Expedition will be made publicly available and adhere to international standards and the FAIR data principles, meaning that data are findable, accessible, interoperable, and reusable. Discussions are ongoing about the potential to utilize novel technologies and tools including real-time salmon stock identification at sea, environmental DNA (eDNA), genomic salmon health assessments, remote sensing technologies, and ocean gliders/Saildrones. We are also working on a comprehensive communications plan that will engage target audiences in this important work.

The novel technologies and tools applied as part of the 2022 Expedition will provide new salmon and environmental observations from across the North Pacific Ocean and facilitate their rapid synthesis. This will lay the foundation from which to design an international ocean monitoring and ocean research system required to inform fisheries management in a highly uncertain environment. This long-term monitoring system will improve forecasts and vulnerability assessments that will support effective responses to the increasingly unpredictable state of salmon stocks. It will also provide more accurate salmon distribution models to inform high seas enforcement activities. Furthermore, it will inform long-term investments in hatcheries and in-season strategies for releases by helping to understand the interactions of hatchery fish with native salmon stocks and the overall ecosystem. Finally, these efforts will provide baseline data to inform processes related to the implementation of BBNJ (Biodiversity Beyond National Jurisdictions) to help understand the future impacts of a growing ocean economy. The 2022 expedition will set the stage for this important work as salmon and their ecosystems face an unpredictable future.

\section{REFERENCES}

Myers, K.W., J.R. Irvine, E.A. Logerwell, S. Urawa, S.V. Naydenko, A.V. Zavolokin, and N.D. Davis. 2016. Pacific salmon and steelhead: life in a changing winter ocean. N. Pac. Anadr. Fish Comm. Bull. 6: 113-138. (Available at https://npafc.org)

Pakhomov, E.A., C. Deeg, S. Esenkulova, G. Foley, B.P.V. Hunt, A. Ivanov, H.K. Jung, G. Kantakov, A. Kanzeparova, A. Khleborodov, C. Neville, V. Radchenko, I. Shurpa, A. Slabinsky, A. Somov, S. Urawa, A. Vazhova, P.S. Vishnu, C. Waters, L. Weitkamp, M. Zuev, and R. Beamish. 2019. Summary of preliminary findings of the International Gulf of Alaska expedition onboard the R/V Professor Kaganovskiy during February 16-March 18, 2019. N. Pac. Anadr. Fish Comm. Doc. 1858. 25 pp. (Available at https://npafc.org)

Somov, A., T. Blaine, C.M. Deeg, S. Esenkulova, T.J. Frost, S. Garcia, I.V. Grigorov, B.P.V. Hunt, A. Kanzeparova, R.V. LaForge, J.E. Lerner, N. Mahara, C.M. Neville, E.A. Pakhomov, B. Riddell, W.W. Strasburger, and R.J. Beamish. 2020. Preliminary findings of the second salmon Gulf of Alaska expedition onboard the R/V Pacific Legacy March 11-April 7, 2020 as part of the International Year of the Salmon. N. Pac. Anadr. Fish Comm. Doc. 1930 (Rev. 1). 48 pp. (Available at https://npafc.org) 